\title{
Mitochondria Are the Source of Hydrogen Peroxide for Dynamic Brain-Cell Signaling
}

\author{
Li Bao, ${ }^{1,2}$ Marat V. Avshalumov, ${ }^{1}$ Jyoti C. Patel, ${ }^{1}$ Christian R. Lee, ${ }^{1}$ Evan W. Miller, ${ }^{3}$ Christopher J. Chang, ${ }^{3,4}$ \\ and Margaret E. Rice ${ }^{1,2}$ \\ Departments of ${ }^{1}$ Neurosurgery and ${ }^{2}$ Physiology and Neuroscience, New York University School of Medicine, New York, New York 10016, and ${ }^{3}$ Department \\ of Chemistry and ${ }^{4}$ Howard Hughes Medical Institute, University of California, Berkeley, California 94720
}

Hydrogen peroxide $\left(\mathrm{H}_{2} \mathrm{O}_{2}\right)$ is emerging as a ubiquitous small-molecule messenger in biology, particularly in the brain, but underlying mechanisms of peroxide signaling remain an open frontier for study. For example, dynamic dopamine transmission in dorsolateral striatum is regulated on a subsecond timescale by glutamate via $\mathrm{H}_{2} \mathrm{O}_{2}$ signaling, which activates ATP-sensitive potassium $\left(\mathrm{K}_{\text {ATP }}\right)$ channels to inhibit dopamine release. However, the origin of this modulatory $\mathrm{H}_{2} \mathrm{O}_{2}$ has been elusive. Here we addressed three possible sources of $\mathrm{H}_{2} \mathrm{O}_{2}$ produced for rapid neuronal signaling in striatum: mitochondrial respiration, monoamine oxidase (MAO), and NADPH oxidase (Nox). Evoked dopamine release in guinea-pig striatal slices was monitored with carbon-fiber microelectrodes and fast-scan cyclic voltammetry. Using direct fluorescence imaging of $\mathrm{H}_{2} \mathrm{O}_{2}$ and tissue analysis of ATP, we found that coapplication of rotenone $(50 \mathrm{nM})$, a mitochondrial complex I inhibitor, and succinate $(5 \mathrm{~mm})$, a complex II substrate, limited $\mathrm{H}_{2} \mathrm{O}_{2}$ production, but maintained tissue ATP content. Strikingly, coapplication of rotenone and succinate also prevented glutamate-dependent regulation of dopamine release, implicating mitochondrial $\mathrm{H}_{2} \mathrm{O}_{2}$ in release modulation. In contrast, inhibitors of $\mathrm{MAO}$ or Nox had no effect on dopamine release, suggesting a limited role for these metabolic enzymes in rapid $\mathrm{H}_{2} \mathrm{O}_{2}$ production in the striatum. These data provide the first demonstration that respiring mitochondria are the primary source of $\mathrm{H}_{2} \mathrm{O}_{2}$ generation for dynamic neuronal signaling.

\section{Introduction}

Beginning with Ramón y Cajal's discovery of gaps between neurons (Ramón y Cajal, 1909), neurotransmission has been considered to be "hard-wired," with point-to-point synaptic connections providing interneuronal communication. However, nonsynaptic communication by diffusion-based volume transmission (Fuxe and Agnati, 1991; Vizi, 2000) is also increasingly appreciated as playing a critical role. For example, dopamine, a key motor-system transmitter in the striatum, acts by volume transmission to activate predominantly extrasynaptic receptors after synaptic release (Sesack et al., 1994; Yung et al., 1995; Cragg and Rice, 2004; Rice and Cragg, 2008). In this context, an emerging diffusible messenger is the reactive oxygen species (ROS), hydrogen peroxide $\left(\mathrm{H}_{2} \mathrm{O}_{2}\right)$ (Atkins and Sweatt, 1999; Avshalumov et al., 2003, 2007; Avshalumov and Rice, 2003; Kamsler and Segal, 2004). Importantly, $\mathrm{H}_{2} \mathrm{O}_{2}$ mediates the regulation of striatal dopamine release by the classical synaptic transmitter, glutamate (Avshalumov et al., 2003, 2008), in the absence of glutamate

\footnotetext{
Received April 8, 2009; accepted May 19, 2009

These studies were supported by National Institutes of Health ( $\mathrm{NHH}$-National Institute of Neurological Disorders and Stroke Grants NS-36362 and NS-45325 (M.E.R.), the National Parkinson Foundation (M.E.R.), and NIH-National Institute of General Medical Sciences Grant GM 79465 (C.J.C.). C.J.C. is an Investigator with the Howard Hughes Medical Institute. We were also supported by and are grateful to the Turner Biosystems Luminometer Grants Program for the grant of a TD-20/20 Luminometer.

Correspondence should be addressed to Dr. Margaret E. Rice, Department of Physiology and Neuroscience, New York University School of Medicine, 550 First Avenue, New York, NY 10016. E-mail: margaret.rice@nyu.edu.

M. V. Avshalumov's present address: Department of Neurosurgery, Mount Sinai Medical Center, New York, NY 10029.

DOI:10.1523/JNEUROSCI.1706-09.2009

Copyright $\odot 2009$ Society for Neuroscience $\quad$ 0270-6474/09/299002-09\$15.00/0
}

synapses or ionotropic receptors on dopaminergic axons (Smith and Bolam, 1990; Bernard et al., 1997; Bernard and Bolam, 1998; Chen et al., 1998).

Evidence for $\mathrm{H}_{2} \mathrm{O}_{2}$ involvement in modulation of striatal dopamine release by glutamate comes from several avenues. Blockade of glutamatergic AMPA receptors (AMPARs) causes an increase in locally evoked dopamine release, which is prevented by the $\mathrm{H}_{2} \mathrm{O}_{2}$-metabolizing enzymes glutathione ( $\mathrm{GSH}$ ) peroxidase or catalase (Avshalumov et al., 2003). Conversely, locally evoked dopamine release is suppressed when $\mathrm{H}_{2} \mathrm{O}_{2}$ levels are amplified by inhibition of GSH peroxidase; this suppression is lost when AMPARs are blocked, demonstrating that modulatory $\mathrm{H}_{2} \mathrm{O}_{2}$ generation is glutamate dependent (Avshalumov et al., 2003). The mechanism of release inhibition by $\mathrm{H}_{2} \mathrm{O}_{2}$ is the activation of ATP-sensitive $\mathrm{K}^{+}\left(\mathrm{K}_{\mathrm{ATP}}\right)$ channels (Avshalumov and Rice, 2003; Avshalumov et al., 2008), and key cellular sources of modulatory $\mathrm{H}_{2} \mathrm{O}_{2}$ are striatal medium spiny neurons (MSNs) (Avshalumov et al., 2008).

The subcellular source of $\mathrm{H}_{2} \mathrm{O}_{2}$ generation has been elusive, however. Three potential sources might contribute. The first is mitochondrial respiration, which produces superoxide anion $\left(\cdot \mathrm{O}_{2}{ }^{-}\right)$by the one-electron reduction of molecular oxygen $\left(\mathrm{O}_{2}\right)$, with subsequent conversion of $\cdot \mathrm{O}_{2}{ }^{-}$to $\mathrm{H}_{2} \mathrm{O}_{2}$ by superoxide dismutase or spontaneous dismutation (Boveris et al., 1973; AdamVizi, 2005). The second is monoamine oxidase (MAO), which catalyzes deamination of dopamine through a two-electron reduction of $\mathrm{O}_{2}$ to $\mathrm{H}_{2} \mathrm{O}_{2}$ (Maker et al., 1981) and is expressed abundantly in striatum (Azzaro et al., 1985). The third is NADPH oxidase (Nox), a family of enzymes that catalyze the one-electron 


\section{a Control Succinate}

Washout

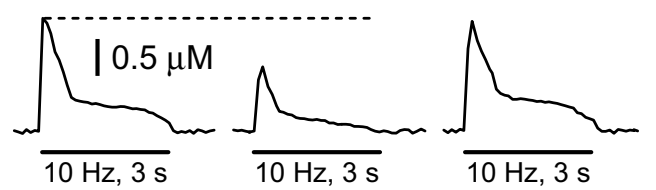

b

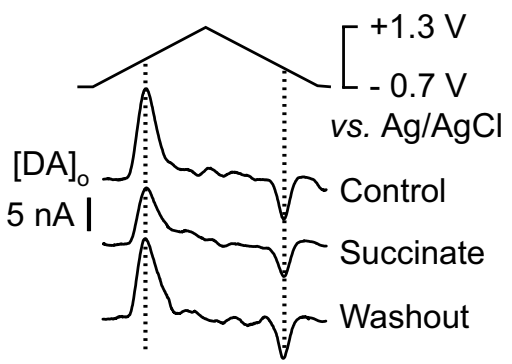

C

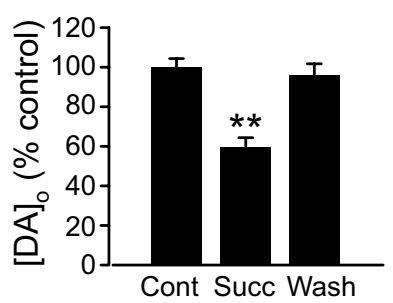

d Catalase Cat+Succ

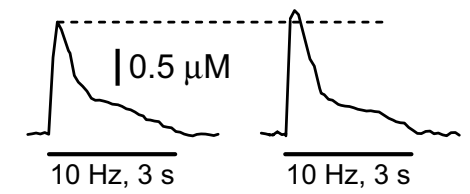

e


Figure 1. Reversible inhibition of axonal dopamine release in the presence of succinate requires $\mathrm{H}_{2} \mathrm{O}_{2}$ and $\mathrm{K}_{\text {ATP }}$ channel activation. $\boldsymbol{a}$, Representative [DA] ${ }_{0}$ versus time profiles during pulse-train stimulation ( 30 pulses, $10 \mathrm{~Hz}$ ) at a given striatal site under control conditions, in $5 \mathrm{~mm}$ succinate, and after succinate washout. $\boldsymbol{b}$, Voltammograms taken at the peak of the release response under the conditions in $\boldsymbol{a}$; dashed lines indicate oxidation and reduction peak potentials for dopamine during calibration used to confirm that the monitored substance was dopamine. c, Average evoked [DA] ${ }_{0}$ normalized to control (100\%) for each slice. Succinate (Succ) caused a decrease in evoked $[D A]_{0}\left({ }^{* *} p<0.01\right.$ vs control; $\left.n=5\right)$ that was reversed by succinate washout (Wash) $(p>0.05 \mathrm{vs} \mathrm{control;} n=5) . \boldsymbol{d}$, Representative evoked $[\mathrm{DA}]_{0}$ in the presence of catalase $(\mathrm{Cat}, 500 \mathrm{U} / \mathrm{ml})$ and during exposure to succinate in the continued presence of catalase (Cat+Succ). $\boldsymbol{e}$, Representative evoked $[D A]_{0}$ in the presence of glibenclamide (Glib, $3 \mu \mathrm{M}$ ), a $\mathrm{K}_{\text {ATP }}$ channel blocker and during exposure to succinate in the continued presence of catalase (Cat + Succ). $\boldsymbol{f}$, Averaged evoked $[D A]_{0}$ normalized to control showing prevention of succinate-induced suppression by catalase $(p>0.05$, + Succ vs (at; $n=5$ ) or by glibenclamide ( $p>0.05$, Succ vs Glib; $n=6$ ).

reduction of $\mathrm{O}_{2}$ to form $\cdot \mathrm{O}_{2}{ }^{-}$and consequently $\mathrm{H}_{2} \mathrm{O}_{2}$ (Lambeth, 2004; Infanger et al., 2006; Rhee, 2006; Bedard and Krause, 2007). Nox has been implicated in a variety of signaling pathways and is also found in striatum (Infanger et al., 2006; Kishida and Klann, 2007).

Here, we examined contributions from these subcellular sources to rapid $\mathrm{H}_{2} \mathrm{O}_{2}$-dependent signaling. Synaptic release of dopamine was elicited by pulse-train stimulation in guinea-pig striatal slices; manipulation of mitochondrial $\mathrm{H}_{2} \mathrm{O}_{2}$ generation was monitored in MSNs using fluorescence imaging. The data show that mitochondrial respiration is the primary subcellular source of modulatory $\mathrm{H}_{2} \mathrm{O}_{2}$ and reveal an exquisite interplay among neuronal activity, mitochondrial respiration, and transmitter release, bridged by a unique signaling molecule, $\mathrm{H}_{2} \mathrm{O}_{2}$.

\section{Materials and Methods}

Brain slice preparation. All animal handling procedures were in accordance with National Institutes of Health guidelines and were approved by the New York University School of Medicine Animal Care and Use Committee. Young adult guinea pigs (male, Hartley, 150-250 g) were deeply anesthetized with $50 \mathrm{mg} / \mathrm{kg}$ (i.p.) pentobarbital and decapitated. For voltammetric recording, coronal brain slices $(400 \mu \mathrm{m})$ containing striatum were prepared as described previously (Chen and Rice, 2001; Avshalumov et al., 2003). In some experiments, ROS generation was monitored in striatal MSNs. Brain slices for these studies were prepared from animals that were perfused intracardially with ice-cold modified

artificial CSF (ACSF) (Bao et al., 2005; Avshalumov et al., 2008). Slices were maintained in a holding chamber for at least $1 \mathrm{~h}$ at room temperature before experimentation in HEPESbuffered ACSF containing (in mM): $120 \mathrm{NaCl}, 5$ $\mathrm{KCl}, 20 \mathrm{NaHCO}_{3}, 6.7$ HEPES acid, 3.3 HEPES salt, $2 \mathrm{CaCl}_{2}, 2 \mathrm{MgSO}_{4}$, and 10 glucose, equilibrated with $95 \% \mathrm{O}_{2} / 5 \% \mathrm{CO}_{2}$ (Rice et al., 1994). For recording, slices were transferred to a submersion chamber at $32^{\circ} \mathrm{C}$ and superfused at 1.2 $\mathrm{ml} / \mathrm{min}$ with bicarbonate-buffered ACSF containing (in $\mathrm{mm}$ ): $124 \mathrm{NaCl}, 3.7 \mathrm{KCl}, 26$ $\mathrm{NaHCO}_{3}, 2.4 \mathrm{CaCl}_{2}, 1.3 \mathrm{MgSO}_{4}, 1.3 \mathrm{KH}_{2} \mathrm{PO}_{4}$, and 10 glucose, equilibrated with $95 \% \mathrm{O}_{2} / 5 \%$ $\mathrm{CO}_{2}$ (Rice et al., 1994; Avshalumov et al., 2003). Media osmolarity was $\sim 300 \mathrm{mOsmol} / \mathrm{L}$ (Osmette osmometer; Precision Systems); in experiments with disodium succinate, osmolarity was maintained by decreasing $\mathrm{NaCl}$.

Voltammetric recording. Axonal dopamine release in dorsolateral striatum was evoked using a surface bipolar stimulating electrode. The resulting increase in extracellular dopamine concentration $\left([\mathrm{DA}]_{\mathrm{o}}\right)$ was monitored using fast-scan cyclic voltammetry (Millar Voltammeter, Queen Mary, University of London, UK) with $8 \mu \mathrm{m}$ carbon-fiber microelectrodes that were either made in-house (Patel et al., 2009) or purchased (MPB Electrodes or WPI). The stimulus was a 30 pulse train $(10 \mathrm{~Hz})$ applied at 10 min intervals; pulse duration was $100 \mu$ s and amplitude was $0.6-0.9 \mathrm{~mA}$. Under these conditions, dopamine release is tetrodotoxin (TTX) sensitive and $\mathrm{Ca}^{2+}$ dependent (Chen and Rice, 2001). Scan rate for fast-scan cyclic voltammetry was $800 \mathrm{~V} / \mathrm{s}$, voltage range was -0.7 to +1.3 $\mathrm{V}$ versus $\mathrm{Ag} / \mathrm{AgCl}$, and sampling interval was $100 \mathrm{~ms}$. Data acquisition and analysis were as described previously (Chen and Rice, 2001).

After a 30 min slice equilibration period in the recording chamber, evoked $[\mathrm{DA}]_{\mathrm{o}}$ was monitored until release was stable for at least three stimulations; once stable, evoked [DA] o was constant for at least $2 \mathrm{~h}$ in ACSF alone. Maximal drug effects were typically seen within 20-40 min of application with stable release levels recorded subsequently. Released dopamine was identified by characteristic oxidation and reduction peak potentials (Chen and Rice, 2001; Bao et al., 2005) (Fig. 1b); [DA] was calculated from post-experimental electrode calibration in the recording chamber at $32^{\circ} \mathrm{C}$ in all media used in a given experiment (e.g., ACSF and ACSF plus succinate). All agents used were screened initially for possible interference with dopamine detection. No interference was seen with any agents reported here, although several Nox inhibitors did interfere, as noted in Results, and were excluded from further testing.

Fluorescence imaging of $\mathrm{H}_{2} \mathrm{O}_{2}$. Intracellular $\mathrm{H}_{2} \mathrm{O}_{2}$ generation was monitored using fluorescence imaging with Redoxfluor-1 (RF1), which is a reversible fluorescein-based dye coupled to a disulfide/dithiol switch that permits reversible activation of the dye by ROS (Miller et al., 2007a). This ROS-sensitive dye was loaded into individual cells via a patch pipette used for whole-cell recording (Avshalumov et al., 2005, 2008; Bao et al., 2005). Striatal MSNs were identified morphologically (Fig. $2 b$ ) and by their electrophysiological characteristics, as previously described (Bao et al., 2005; Avshalumov et al., 2008). The intracellular solution contained (in mM): $120 \mathrm{~K}$-gluconate, $20 \mathrm{KCl}, 2 \mathrm{MgCl}_{2}, 10 \mathrm{Na}$-HEPES, $10 \mathrm{EGTA}, 3$ $\mathrm{Na}_{2}$-ATP, 0.2 GTP; $\mathrm{pH}$ adjusted to 7.2-7.3 with $\mathrm{KOH}$; Alexa Red (0.1\%) was also included for cell visualization and $\mathrm{RF} 1(5 \mu \mathrm{M})$ for $\mathrm{H}_{2} \mathrm{O}_{2}$ imaging. After whole-cell configuration was obtained, cells were held for $\sim 20 \mathrm{~min}$ to allow dye infiltration. Images were acquired using a Cascade chargecoupled device camera (Roper Scientific) and an illuminator and monochrometer from Photon Technology International and were analyzed 
using ImageMaster software (Photon Technology International), as described previously (Avshalumov et al., 2005, 2008; Bao et al., 2005). Fluorescence intensity for $535 \mathrm{~nm}$ emission in background-subtracted frame averages were normalized; average data are presented as $[($ intensity - basal $) /($ basal $)] \times 100 \%$.

Tissue ATP content. Striatal ATP content was determined in separate experiments using a TD-20/20 Luminometer (Turner Biosystems) with an Enlighten ATP assay kit (Promega), as previously described (Bao et al., 2005). This method is based on the luciferase-catalyzed reaction of ATP with luciferin; light emission was at $560 \mathrm{~nm}$. Tissue ATP content was determined in unfrozen tissue samples from striatal slices; ATP content is given as micromoles per gram of tissue wet weight (Bao et al., 2005). To mirror the paradigm used for dopamine release studies, slices were incubated in ACSF for $60 \mathrm{~min}$, then transferred to chambers containing $50 \mathrm{~nm}$ rotenone, 5 mm succinate, or $50 \mathrm{~nm}$ rotenone plus $5 \mathrm{~mm}$ succinate in ACSF for $90 \mathrm{~min}$, all at $32^{\circ} \mathrm{C}$. Paired control samples were taken from the contralateral striatum after incubation in ACSF alone for the same time periods.

Drugs and chemicals. Disodium succinate, glibenclamide, rotenone, mercaptosuccinic acid, pargyline hydrochloride, clorgyline, phenylarsine oxide (PAO), and all ACSF components were from Sigma, GYKI-52466 was from Tocris Bioscience, and catalase (bovine liver) was from Calbiochem. Stock solutions of glibenclamide, rotenone, and $\mathrm{PAO}$ were made in DMSO ( $\leq 0.1 \%$ final DMSO concentration in ACSF), and stock solutions of GYKI-52466 were made in $0.1 \mathrm{M} \mathrm{HCl}$; neither vehicle alone altered evoked $[\mathrm{DA}]_{\mathrm{o}}$.

Statistical analysis. Voltammetric data are given as mean $\pm \operatorname{SEM}(n=$ number of slices) and illustrated as percentage of control. For each slice, the last three control records obtained before drug application were averaged and the mean peak $[\mathrm{DA}]_{\mathrm{o}}$ was taken as $100 \%$ for that slice. Differences in peak evoked $[\mathrm{DA}]_{\mathrm{o}}$ between the effect of a single test agent and samesite controls were assessed using paired Student's $t$ test. One-way ANOVA with Dunnett's post hoc analysis was used to assess the effect of multiple agents, to assess the time course of drug effects, and to compare drug-induced changes under different conditions. Paired $t$ tests were used to assess ATP content data and one-way ANOVA was used to assess RF1 fluorescence data. Differences were considered to be significant for $p<0.05$.

\section{Results}

\section{Mitochondrial $\mathrm{H}_{2} \mathrm{O}_{2}$ generation}

In isolated mitochondria, partial inhibi-

tion of mitochondrial respiration by rotenone, a complex I inhibitor, causes an increase in $\mathrm{H}_{2} \mathrm{O}_{2}$ production by complex I (Servais et al., 2003; Sherer et al., 2003). Succinate, a complex II substrate, also causes an increase in $\mathrm{H}_{2} \mathrm{O}_{2}$ production by complex I by reverse electron flow from complex II to complex I; this increase in $\mathrm{H}_{2} \mathrm{O}_{2}$ generation is blocked by rotenone at nanomolar concentrations (Liu et al., 2002; Servais et al., 2003; Gyulkhandanyan and Pennefather, 2004). Our previous work showed that nano-

a

b

d

e 0.05 vs control; $n=6)$.
Rotenone
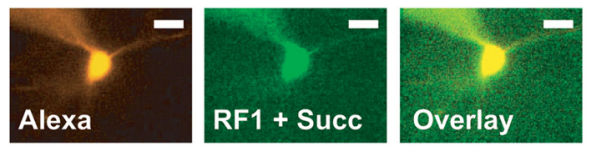

Succinate
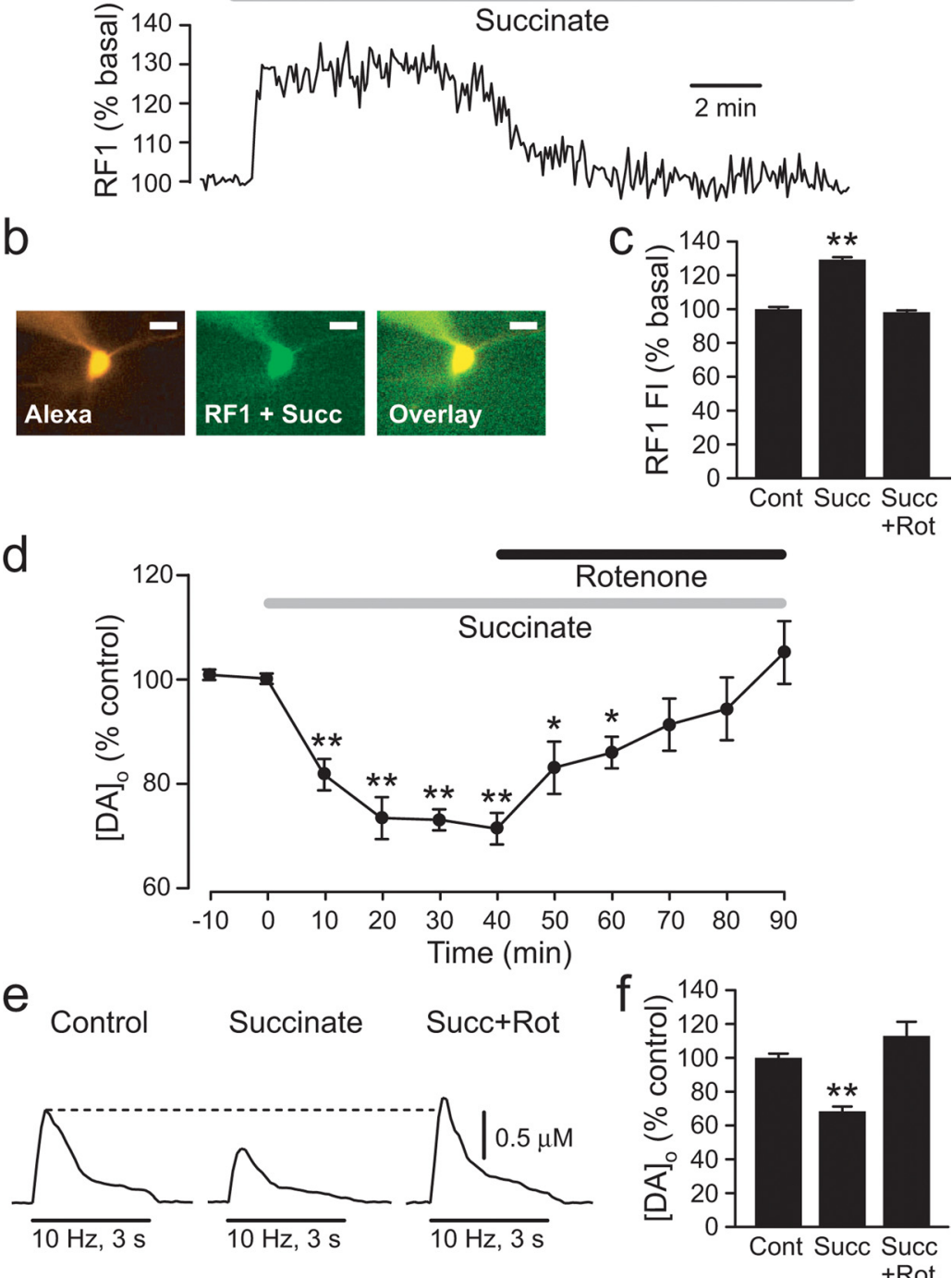

Figure 2. Succinate-induced $\mathrm{H}_{2} \mathrm{O}_{2}$ generation in striatal neurons can be reversed by rotenone. $\boldsymbol{a}$, Superfusion of 5 mm succinate caused an increase in fluorescence intensity $(\mathrm{FI})$ of the reversible $\mathrm{H}_{2} \mathrm{O}_{2}$-sensitive dye, $\mathrm{RF} 1$, in a MSN in a striatal slice. The Fl increase was reversed by $50 \mathrm{~nm}$ rotenone. $\boldsymbol{b}$, Morphological identification of the neuron in $\boldsymbol{a}$ using Alexa Red. Overlay of this image with peak RF1fluorescence intensity in this cell during succinate (Succ) exposure confirms that the data recorded were from an MSN (Scale bar, $20 \mu \mathrm{m}$ ). c, Average RF1 FI normalized to basal Fl under control conditions (Cont; 100\%). Succinate caused an increase in RF1 Fl over basal $\left({ }^{* *} p<0.01\right.$ vs control; $\left.n=7\right)$ that was reversed by rotenone in the continued presence of succinate (Succ + Rot; $p>0.05$ vs control; $n=7)$. $\boldsymbol{d}-\boldsymbol{f}$, Functional consequences of succinate and succinate plus rotenone on dopamine release. $\boldsymbol{d}$, Superfusion of $5 \mathrm{~mm}$ succinate caused a suppression of $[\mathrm{DA}]_{0}$ evoked at $10 \mathrm{~min}$ intervals by pulse-train stimulation; suppression of evoked $[\mathrm{DA}]_{0}$ was reversed by $50 \mathrm{~nm}$ rotenone $\left({ }^{*} p<0.05,{ }^{* *} p<0.01\right.$ vs averaged same-site control; $\left.n=6\right)$. Note difference in time scale between imaging in superficial MSNs and the effect on dopamine release, which is a population response that includes deeper tissue levels. $\boldsymbol{e}$, Representative evoked [DA] at a single striatal site during pulse-train stimulation ( 30 pulses, $10 \mathrm{~Hz}$ ) under control conditions, in $5 \mathrm{~mm}$ succinate, and after application of $50 \mathrm{~nm}$ rotenone in the continued presence of succinate. $\boldsymbol{f}$, Average peak $[\mathrm{DA}]_{0}$, normalized to control $(100 \%)$ during pulse-train stimulation under each condition. Succinate-induced inhibition of evoked $[\mathrm{DA}]_{0}(p<0.05$ vs control; $n=6)$ was reversed by the addition of rotenone in the continued presence of succinate ( $p>$

molar rotenone also produces functionally relevant levels of $\mathrm{H}_{2} \mathrm{O}_{2}$ in MSNs in the complex neuron-glial microenvironment of striatal slices (Bao et al., 2005). This unstimulated increase in mitochondrial $\mathrm{H}_{2} \mathrm{O}_{2}$ generation leads to suppression of evoked dopamine release in striatal slices that is prevented by catalase and by $\mathrm{K}_{\mathrm{ATP}}$-channel blockade.

In light of those data, we asked whether succinate-dependent $\mathrm{H}_{2} \mathrm{O}_{2}$ generation also had the functional consequence of suppressing dopamine release in striatal slices. Importantly, Yodoya 
et al. (2006) have shown that succinate can enter neurons via $\mathrm{Na}^{+}$-coupled carboxylate transporters, making this experiment feasible. Under control conditions, the average $[\mathrm{DA}]_{\mathrm{o}}$ evoked by local pulse-train stimulation $(30$ pulses, $10 \mathrm{~Hz}$ ) was $1.18 \pm 0.07$ $\mu \mathrm{M}$ and was stable for at least $2 \mathrm{~h}$ when elicited at $10 \mathrm{~min}$ intervals. However, when slices were exposed to $5 \mathrm{~mm}$ succinate, the concentration examined previously with isolated mitochondria (Liu et al., 2002; Gyulkhandanyan and Pennefather, 2004), evoked $[\mathrm{DA}]_{\mathrm{o}}$ fell by $20-30 \%(p<0.01$ vs same site control; $n=6)$ within $10 \mathrm{~min}$, with a maximum decrease of $30-40 \%(p<0.01$; $n=6$ ) seen after $30 \mathrm{~min}$ (Fig. $1 a-c$, see also Fig. $2 d$ ). Importantly, succinate-induced DA release inhibition was reversible, with a return of evoked $[\mathrm{DA}]_{\mathrm{o}}$ to control levels after succinate washout (typically 40 min wash) ( $p>0.05$ washout vs control; $n=6$ ) (Fig. $1 a-c)$. A lower concentration of succinate $(1 \mathrm{~mm})$ had no effect on evoked $[\mathrm{DA}]_{\mathrm{o}}$ after 60 min exposure ( $p>0.05$ vs control; $n=5)$, whereas higher concentrations of succinate (10-50 $\mathrm{mM}$ ) caused a progressive and irreversible decline in evoked $[\mathrm{DA}]_{\mathrm{o}}$. Consequently, $5 \mathrm{~mm}$ succinate was used in all subsequent studies.

Demonstrating that succinate-induced DA release suppression required $\mathrm{H}_{2} \mathrm{O}_{2}$ generation, the effect of $5 \mathrm{~mm}$ succinate on evoked $[\mathrm{DA}]_{\mathrm{o}}$ was prevented by catalase $(500 \mathrm{U} / \mathrm{ml})(n=6, p>$ 0.05 ) (Fig. $1 d, f)$, which has been shown previously to prevent $\mathrm{H}_{2} \mathrm{O}_{2}$-dependent suppression of DA release (Avshalumov et al., 2003, 2007). Heat-inactivated catalase did not alter the effect of succinate on evoked $[\mathrm{DA}]_{\mathrm{o}}$ (not illustrated). To ascertain whether the $\mathrm{H}_{2} \mathrm{O}_{2}$-dependent effect of succinate was mediated by $\mathrm{K}_{\mathrm{ATP}}$ channels, we examined whether DA release suppression could be prevented by glibenclamide, a $\mathrm{K}_{\mathrm{ATP}}$-channel blocker. In the presence of glibenclamide $(3 \mu \mathrm{M})$ (Avshalumov and Rice, 2003 ), the effect of $5 \mathrm{~mm}$ succinate on evoked [DA $]_{\mathrm{o}}$ was lost (Fig. $1 e, f)(p>0.05 ; n=6)$.

To confirm that exogenously applied succinate, like rotenone (Bao et al., 2005), can indeed increase $\mathrm{H}_{2} \mathrm{O}_{2}$ generation in brain slices, we directly visualized intracellular $\mathrm{H}_{2} \mathrm{O}_{2}$ produced in striatal MSNs using RF1, a recently described imaging dye that is reversibly activated by $\mathrm{H}_{2} \mathrm{O}_{2}$ and other ROS (Miller et al., 2007a). The reversibility of RF1 offers a distinct advantage over other available dyes like DCF (dichlorodihydrofluorescein) that undergo irreversible activation by ROS (Avshalumov et al., 2007). Succinate $(5 \mathrm{~mm})$ caused a robust increase in RF1 fluorescence, indicating increased ROS levels $(p<0.01 ; n=7)$ (Fig. $2 a-c)$. The succinate-induced increase in RF1 fluorescence was prevented by catalase $(500 \mathrm{U} / \mathrm{ml})$, confirming the $\mathrm{H}_{2} \mathrm{O}_{2}$ dependence of the $\mathrm{RF} 1$ response (not illustrated).

Importantly, the succinate-induced increase in RF1 fluorescence was reversed by the addition of $50 \mathrm{~nm}$ rotenone, which is near the $\mathrm{IC}_{50}$ for inhibition of mitochondrial complex I (Betarbet et al., 2000; Votyakova and Reynolds, 2001) ( $p>0.05$ succinate + rotenone vs control; $n=7$ ) (Fig. 2a,c). No decrement in RF1 fluorescence was seen over the same time frame in succinate alone (not illustrated). These data demonstrate that, as in isolated mitochondria (Liu et al., 2002; Servais et al., 2003; Gyulkhandanyan and Pennefather, 2004), rotenone plus succinate inhibits mitochondrial $\mathrm{H}_{2} \mathrm{O}_{2}$ generation in striatal neurons.

We then examined the effect of $50 \mathrm{nM}$ rotenone on the $\mathrm{H}_{2} \mathrm{O}_{2}$ dependent inhibition of dopamine release by succinate. Again, exposure of striatal slices to $5 \mathrm{~mm}$ succinate caused a significant suppression of evoked $[\mathrm{DA}]_{\mathrm{o}}$ within $10 \mathrm{~min}(p<0.01 ; n=6)$ (Fig. 2d). Consistent with our RF1 imaging data (Fig. 2a,c), rotenone reversed the succinate-induced inhibition of evoked $[\mathrm{DA}]_{\mathrm{o}}$ to control levels in the continued presence of succinate $(p>0.05$

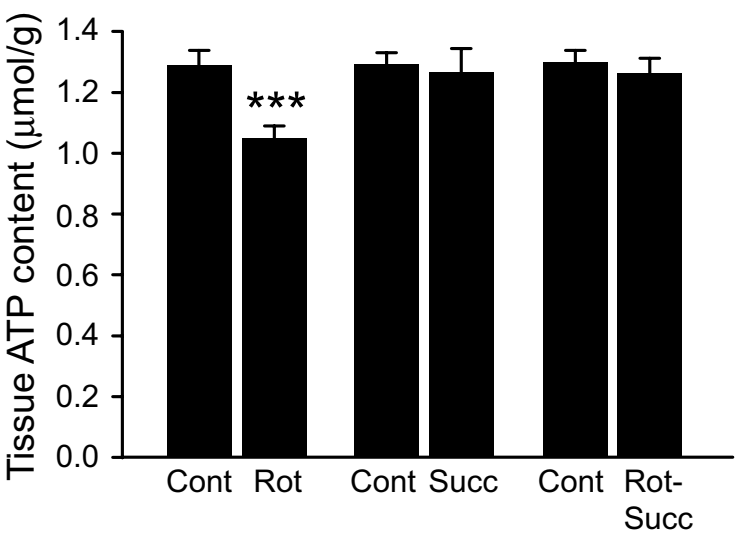

Figure 3. Striatal ATP content during prolonged exposure to rotenone and succinate. Average ATP content in samples of dorsal striatum from slices after $90 \mathrm{~min}$ in $50 \mathrm{~nm}$ rotenone (Rot), 5 mm succinate (Succ), or rotenone and succinate (Rot-Succ). Striatal ATP content was lower in slices incubated in rotenone than in paired control slices (Cont) in ASCF alone $\left({ }^{* * *} p<0.001\right.$ vs paired controls; $n=10)$. However, ATP content was unaltered after 90 min in succinate alone ( $p>0.05$ vs paired controls; $n=6$ ) or in Rot-Succ ( $p>0.05$ vs paired controls; $n=27$ ).

succinate + rotenone vs control; $n=6)($ Fig. $2 d-f)$, demonstrating the loss of $\mathrm{H}_{2} \mathrm{O}_{2}$-dependent dopamine release suppression in the presence of rotenone plus succinate. It should be noted that the time course of dopamine release suppression by succinate and recovery in succinate + rotenone is prolonged compared with changes in $\mathrm{H}_{2} \mathrm{O}_{2}$ generation indicated by RF1 fluorescence recorded in single MSNs (Fig. 2a,d). This primarily reflects the difference in recording site for the two measurements. Evoked $[D A]_{o}$ reflects a population response so that the time course of pharmacological effects on dopamine release necessarily includes restricted diffusion of agents into a slice. In contrast, imaging data are taken from superficial cells, so that little, if any, tissue penetration is required, leading to a faster response.

\section{Maintenance of tissue ATP content in succinate plus rotenone} We reported previously that striatal ATP content is maintained during $30 \mathrm{~min}$ exposure to $50 \mathrm{~nm}$ rotenone (Bao et al., 2005). In the present studies, we found that when the period of exposure was increased to $90 \mathrm{~min}$, the typical duration of dopamine release experiments, $50 \mathrm{~nm}$ rotenone did cause a small, but significant decrease in striatal ATP content compared with paired controls $(1.05 \pm 0.04 \mu \mathrm{mol} / \mathrm{g}$ in rotenone vs $1.28 \pm 0.05 \mu \mathrm{mol} / \mathrm{g}$ in ACSF; $p<0.001 ; n=10$ slice pairs) (Fig. 3). In contrast, 90 min exposure to $5 \mathrm{~mm}$ succinate caused no change in striatal ATP content $(1.26 \pm 0.04 \mu \mathrm{mol} / \mathrm{g}$ in succinate vs $1.27 \pm 0.04 \mu \mathrm{mol} / \mathrm{g}$ in ACSF; $p>0.05 ; n=6$ slice pairs) (Fig. 3 ). Moreover, when succinate was included with rotenone, striatal ATP content was also maintained during $90 \mathrm{~min}$ incubation $(1.26 \pm 0.05 \mu \mathrm{mol} / \mathrm{g}$ in rotenone + succinate vs $1.29 \pm 0.05 \mu \mathrm{mol} / \mathrm{g}$ in ACSF; $p>0.05 ; n=$ 27 slice pairs) (Fig. 3). Thus, rotenone-succinate not only suppresses $\mathrm{H}_{2} \mathrm{O}_{2}$ generation (Fig. 2) but also maintains ATP production.

\section{Glutamate-dependent modulation of dopamine release requires mitochondrial $\mathrm{H}_{2} \mathrm{O}_{2}$}

Having established that $50 \mathrm{~nm}$ rotenone plus $5 \mathrm{~mm}$ succinate can suppress mitochondrial ROS generation, we examined whether the effect of blocking glutamatergic AMPARs on evoked [DA $]_{\mathrm{o}}$ was altered in the presence of rotenone-succinate. Under control conditions, AMPAR blockade by a selective antagonist, GYKI$52466(50 \mu \mathrm{M})$ (Avshalumov et al., 2003), caused an expected 
$\sim 75 \%$ increase in evoked $[\mathrm{DA}]_{\mathrm{o}}(p<$ 0.001 vs same site control; $n=5$ ) (Fig. $4 a, c)$, which previous work has shown to be entirely $\mathrm{H}_{2} \mathrm{O}_{2}$ dependent (Avshalumov et al., 2003). However, when mitochondrial $\mathrm{H}_{2} \mathrm{O}_{2}$ generation was inhibited by rotenone-succinate, the effect of GYKI52466 on evoked [DA $]_{\text {o }}$ was lost $(p>0.05$ rotenone-succinate + GYKI vs rotenonesuccinate alone; $n=6$ ) (Fig. $4 b, c$ ).

In contrast to the enhancement of pulse-train evoked $[\mathrm{DA}]_{\mathrm{o}}$ seen with AMPAR blockade, a decrease in evoked [DA] is seen when endogenous $\mathrm{H}_{2} \mathrm{O}_{2}$ levels are amplified by inhibition of GSH peroxidase with MCS (1 mm) (Avshalumov et al., 2003, 2005). The effect of MCS is prevented by AMPAR blockade, showing glutamate dependence, and by catalase, confirming $\mathrm{H}_{2} \mathrm{O}_{2}$ dependence (Avshalumov et al., 2003). Here, MCS caused a typical $\sim 35 \%$ decrease in evoked $[\mathrm{DA}]_{\mathrm{o}}$ under control conditions ( $p<0.01$ vs same-site control; $n=5$ ) (Fig. $4 d, f$ ). This effect was prevented when MCS was applied in the presence of rotenone-succinate $(p>0.05$ rotenone-succinate + MCS vs rotenonesuccinate alone; $n=5$ ) (Fig. $4 e, f$ ). These data indicate a primary role for the electron transport chain of mitochondria in the subsecond generation of modulatory $\mathrm{H}_{2} \mathrm{O}_{2}$.

\section{Modulatory $\mathrm{H}_{2} \mathrm{O}_{2}$ is not generated by MAO}

We next examined whether dopamine metabolism by MAO might also be a source of dynamically generated $\mathrm{H}_{2} \mathrm{O}_{2}$. Two MAO isoforms, type $\mathrm{A}$ (MAO-A) and type $\mathrm{B}$ (MAO-B) are found in guinea-pig striatum, consistent with their key roles in dopamine metabolism (Azzaro et al., 1985). We therefore tested a combination of clorgyline, a selective inhibitor of MAO-A, and pargyline, a selective inhibitor of MAO-B at concentrations of $10 \mu \mathrm{M}$ each, based on the use of similar concentrations in brain slices (Rice et al., 1994; Bonnet et al., 2000) that are $\geq 100$-fold higher than that found necessary to inhibit MAO activity in synaptosomes (Azzaro et al., 1985). Application of clorgyline-pargyline alone for $90 \mathrm{~min}$ did not alter evoked $[\mathrm{DA}]_{\mathrm{o}}(p>0.05$ vs same site control; $n=6)$ (Fig. 5a,b). Moreover, the presence of these MAO inhibitors had no effect on the usual increase in evoked [DA] o seen with GYKI52466 ( $p<0.001$ vs clorgyline-pargyline alone, $n=6$; $p>0.05$ for the GYKI-induced increase in evoked $[\mathrm{DA}]_{\mathrm{o}}$ in clorgylinepargyline versus that in ACSF alone; $n=5-6$ ) (Fig. $5 c, d$ ). Similarly, the usual $\sim 35 \%$ decrease in evoked $[\mathrm{DA}]_{\mathrm{o}}$ seen when GSH peroxidase is inhibited by MCS (1 mM) was also unaltered in the presence of clorgyline-pargyline $(p<0.01$ vs clorgylinepargyline alone, $n=6 ; p>0.05$ for the MCS-induced decrease in evoked $[\mathrm{DA}]_{\mathrm{o}}$ in clorgyline-pargyline versus that in ACSF alone; $n=5-6$ ) (Fig. 5e,f). These results indicate that MAO does not contribute to dynamic glutamate and $\mathrm{H}_{2} \mathrm{O}_{2}$-dependent modulation of evoked $[\mathrm{DA}]_{\mathrm{o}}$.
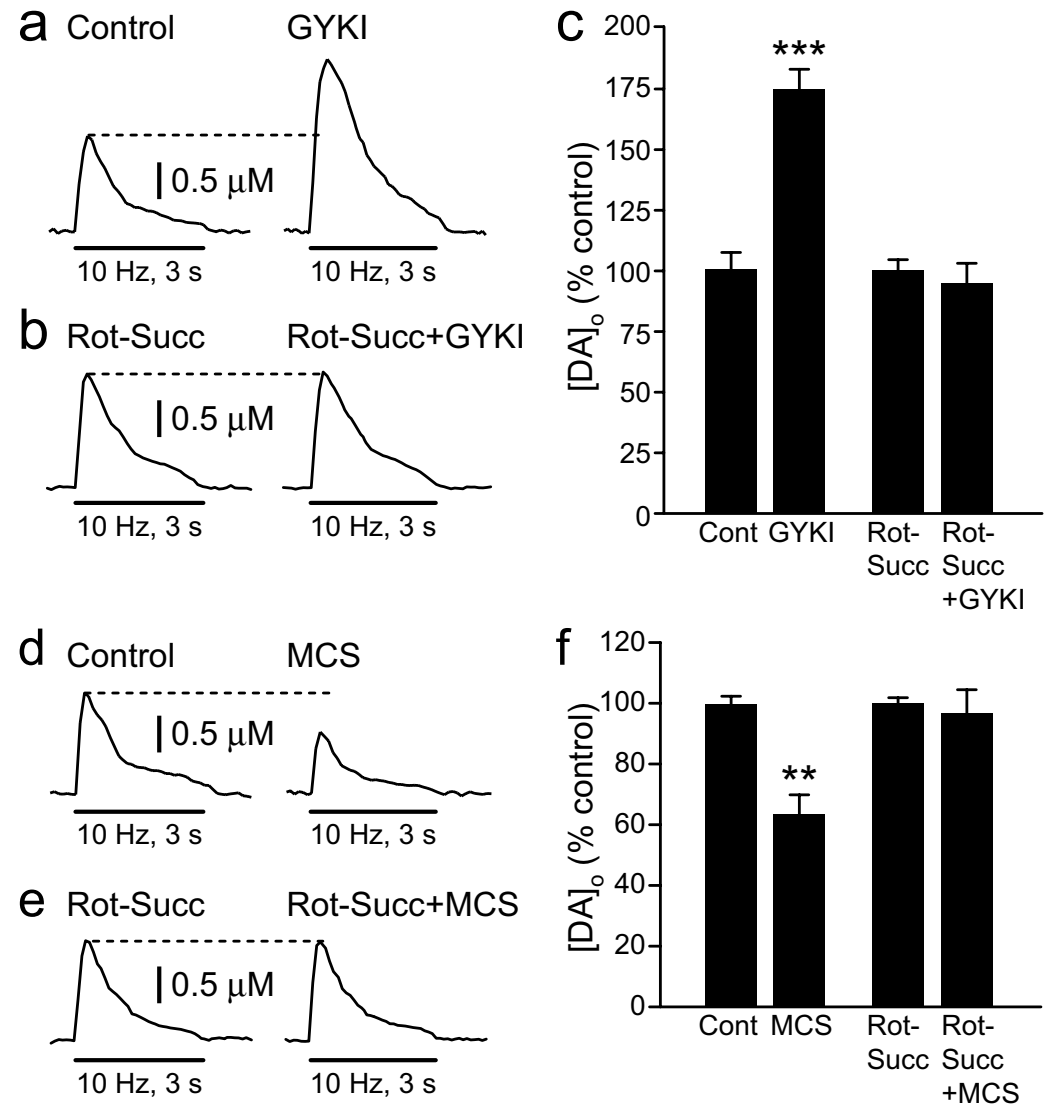

Figure 4. Prevention of AMPAR- and $\mathrm{H}_{2} \mathrm{O}_{2}$-dependent modulation of dopamine release in the presence of rotenone and armalized to the starting condition for each experiment; peak evoked [DA] in ACSF (Cont) was taken as 100\% for comparison with GYKI alone and peak evoked [DA] in Rot-Succ was taken as 100\% for comparison with Rot-Succ + GYKI. GYKI alone caused significant increase in evoked $[\mathrm{DA}]_{0}\left({ }^{* * *} p<0.001\right.$ vs same-site control; $\left.n=5\right)$, which was prevented by rotenone-succinate ( $>0.05$ vs same-site Rot-Succ; $n=6)$. $\boldsymbol{d}, \boldsymbol{e}$, Representative pulse-train evoked [DA] in ACSF alone and in the presence of an presence of Rot-Succ in a different slice $(\boldsymbol{e}) . \boldsymbol{f}$, Average evoked $[D A]_{0}$ normalized to the starting condition for each experiment. MCS alone caused a significant decrease in evoked $[D A]_{0}\left({ }^{* *} p<0.01\right.$ vs same-site control; $\left.n=5\right)$, which was prevented by rotenonesuccinate ( $p>0.05$ vs same-site Rot-Suc; $n=5$ ).

\section{Modulatory $\mathrm{H}_{2} \mathrm{O}_{2}$ is not generated by Nox}

Last, we examined whether Nox family enzymes might contribute to modulatory $\mathrm{H}_{2} \mathrm{O}_{2}$ generation. Of several Nox inhibitors screened, including DPI (diphenyleneiodonium chloride), cadmium(II), AEBSF [4-(2-aminoethyl)-benzenesulfonyl fluoride], and apocynin, only PAO did not interfere with voltammetric detection of evoked dopamine release, making it the only suitable drug for these studies. Significant inhibition of Nox activity in neutrophils is seen with $2 \mu \mathrm{M}$ PAO, with complete inhibition at $10 \mu \mathrm{M}$ (Doussière et al., 2001). We limited the concentration of PAO tested to $10 \mu \mathrm{M}$ because of other reported effects of this thiol-modifying agent, including inhibition of catecholamine release from adrenal chromaffin cells reported for $20 \mu \mathrm{M}$ PAO (Schaefer et al., 1994). Indeed, we found that $100 \mu \mathrm{M}$ PAO caused a precipitous fall in evoked $[\mathrm{DA}]_{\mathrm{o}}$ in striatal slices. In contrast, 10 $\mu \mathrm{M}$ PAO caused a slight, but nonsignificant increase in evoked $[D A]_{o}$ that persisted over 60 min of exposure ( $p>0.05$ vs same site control; $n=7$ ) (Fig. $6 a, b)$, with a fall in evoked [DA] $]_{\mathrm{o}}$ sometimes seen with longer exposure times. Within a $60 \mathrm{~min}$ window, however, the presence of $10 \mu \mathrm{M}$ PAO did not prevent the usual 
a

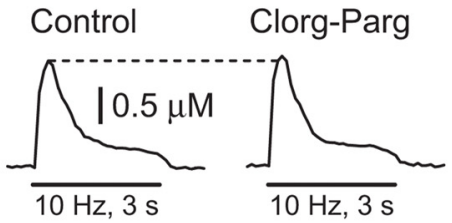

C

Clorg-Parg Clorg-Parg+GYKI

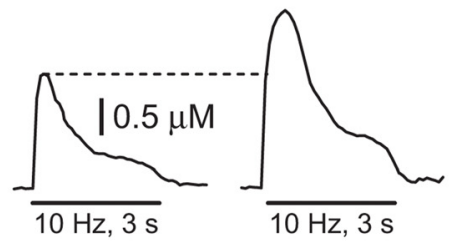

e

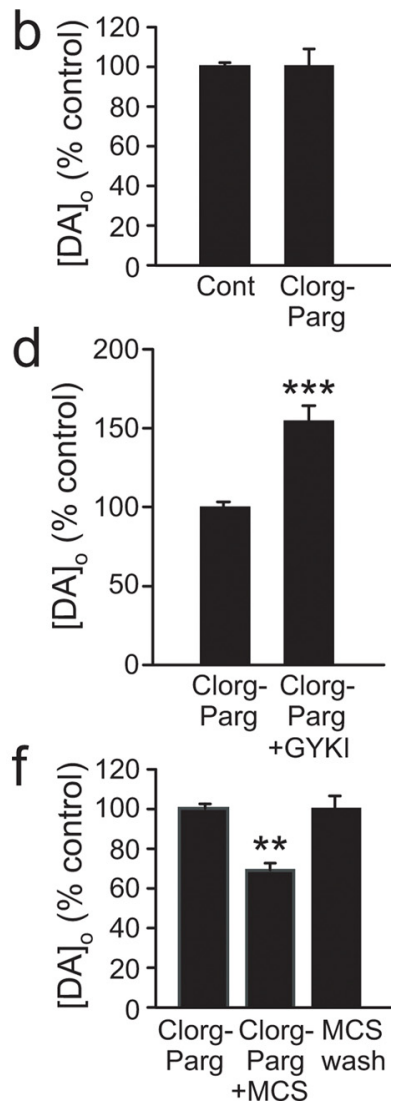

Figure 5. $\mathrm{MAO}$ is not a source of modulatory $\mathrm{H}_{2} \mathrm{O}_{2}$ in striatum. Representative $[D A]_{0}$ evoked by pulse-train stimulation (30 pulses, $10 \mathrm{~Hz}$ ) in ACSF (Control) and in the presence of the MA0 inhibitors, clorgyline and pargyline (Clorg-Parg; $10 \mu \mathrm{m}$ each). $\boldsymbol{b}$, Average evoked [DA] $]_{0}$ normalized to control (100\%) for each slice. Evoked [DA] $]_{0}$ was unaltered by Clorg-Parg $(p>0.05 ; n=6)$. c, Representative dopamine release records in the presence of Clorg-Parg and in GYKI-52466 (GYKI; $50 \mu \mathrm{M}$ ) in the continued presence of Clorg-Parg. d, Average evoked [DA] $]_{0}$, with data normalized to peak evoked [DA] in Clorg-Parg (100\%) for each slice. The increase in evoked [DA] when AMPARs were blocked by GYKI was unaffected by MAO inhibition ( ${ }^{* * *} p<0.001$ vs same-site Clorg-Parg; $n=6)$. e, Representative dopamine release records in Clorg-Parg, in MCS (1 mM) in the continued presence of Clorg + Parg, and in Clorg-Parg after washout of MCS (MCS wash).f, Average evoked [DA $]_{0}$, with data normalized to peak evoked [DA $]_{0}$ in Clorg-Parg (100\%) for each slice. Reversible inhibition of evoked dopamine release when endogenous $\mathrm{H}_{2} \mathrm{O}_{2}$ levels were amplified by MCS was unaffected by MAO inhibition ( ${ }^{* *} p<0.01$ vs same-site Clorg-Parg; $n=6$ ).

increase in evoked $[\mathrm{DA}]_{\mathrm{o}}$ seen with GYKI-52466 $(p<0.001$ vs PAO alone, $n=5 ; p>0.05$ for the GYKI-induced increase in evoked $[\mathrm{DA}]_{\mathrm{o}}$ in PAO vs that in ACSF alone, $n=5$ for each group) or the decrease in evoked $[\mathrm{DA}]_{\mathrm{o}}$ by MCS $(p<0.01 \mathrm{PAO}$ + MCS vs PAO alone; $n=7 ; p>0.05$ for the MCS-induced decrease in evoked $[\mathrm{DA}]_{\mathrm{o}}$ in clorgyline-pargyline versus that in ACSF alone, $n=5-7$ ) (Fig. 6). Together with the efficacy of rotenone-succinate in preventing the consequences of AMPAR blockade and GSH peroxidase inhibition on dopamine release, these results suggest that Nox does not contribute significantly to the generation of modulatory $\mathrm{H}_{2} \mathrm{O}_{2}$ in the striatum.

\section{Discussion}

It is increasingly recognized that $\mathrm{H}_{2} \mathrm{O}_{2}$ can act as a signaling molecule in the CNS and other tissues via a variety of $\mathrm{H}_{2} \mathrm{O}_{2}$ sensing systems, including transcription factors, phosphatases, kinases, and ion channels (Rhee, 2006; Rhee et al., 2005; Kishida and Klann, 2007; Avshalumov et al., 2007; Veal et al., 2007). Many of the pathways are relatively slow, on the order of minutes to hours, with the time course of $\mathrm{H}_{2} \mathrm{O}_{2}$ generation occurring on a similar scale, as seen in cultured neurons exposed to a growth factor [EGF (epidermal growth factor)] that activates intraneuronal, Nox-dependent generation of $\mathrm{H}_{2} \mathrm{O}_{2}$ (Miller et al., 2007b). How-

ever, $\mathrm{H}_{2} \mathrm{O}_{2}$ can also activate ion channels to mediate interneuronal signaling on a subsecond time scale, as seen in the inhibition of striatal dopamine release by glutamatergic activation of AMPARs, consequent $\mathrm{H}_{2} \mathrm{O}_{2}$ generation, and $\mathrm{K}_{\mathrm{ATP}}$-channel opening that occurs within $500 \mathrm{~ms}$ after initiation of a train of stimuli (Avshalumov et al., 2003, 2008; Avshalumov and Rice, 2003). The subcellular source of neuromodulatory $\mathrm{H}_{2} \mathrm{O}_{2}$ must therefore operate on a time scale commensurate with this rapid signaling mechanism.

We show here for the first time that the source of dynamic, glutamate-dependent $\mathrm{H}_{2} \mathrm{O}_{2}$ generation in the striatum is mitochondrial respiration. The effect of AMPAR blockade on evoked dopamine release was completely prevented by a combination of rotenone and succinate that suppressed mitochondrial $\mathrm{H}_{2} \mathrm{O}_{2}$ generation, yet maintained tissue ATP content. Strikingly, the effects of rotenone and succinate on $\mathrm{H}_{2} \mathrm{O}_{2}$ generation in striatal slices (Fig. 2) (Bao et al., 2005) mirror the effects of these agents in isolated mitochondria (Liu et al., 2002; Servais et al., 2003; Gyulkhandanyan and Pennefather, 2004). These data demonstrate that manipulation of mitochondrial complexes I and II leads to functionally relevant $\mathrm{H}_{2} \mathrm{O}_{2}$ production, even in the intricate neuronglia microenvironment of brain slices. Thus, the brain antioxidant network permits signaling by $\mathrm{H}_{2} \mathrm{O}_{2}$ (Avshalumov et al., 2004; Rhee et al., 2005; D'Autréaux and Toledano, 2007), yet at the same time prevents oxidative damage, indicted by the reversibility of dynamic, $\mathrm{H}_{2} \mathrm{O}_{2}$-dependent inhibition of dopamine release (Figs. $1 a, 2 b$ ).

\section{Mitochondrial $\mathrm{H}_{2} \mathrm{O}_{2}$ mediates glutamate-dependent inhibition of striatal dopamine release}

Of the three possible sources of modulatory $\mathrm{H}_{2} \mathrm{O}_{2}$ examined, mitochondria, MAO, and Nox, the mitochondrial electron transport chain could be predicted to be the most likely source, given the rapid responsiveness of mitochondrial respiration to increased cellular activity. Studies in isolated mitochondria suggest that a small but significant percentage of $\mathrm{O}_{2}$ metabolized produces $\cdot \mathrm{O}_{2}{ }^{-}$and $\mathrm{H}_{2} \mathrm{O}_{2}$ (Boveris and Chance, 1973), with increased $\mathrm{O}_{2}$ metabolism causing increased ROS production (Dykens, 1994). The cellular distribution of MAO in the striatum also argues against a significant role in the generation of modulatory $\mathrm{H}_{2} \mathrm{O}_{2}$. Most obviously, MAO-B is found predominantly in glia rather than neurons (Azzaro et al., 1985; Levitt et al., 1985). The predominant neuronal isoform, MAO-A, is expressed in MSNs, but at low levels (Francis et al., 1985). Given that the dopamine transporter (DAT) is expressed by dopaminergic axons but not other cellular elements in the striatum (Nirenberg et al., 1996; Hersch et al., 1997), lack of a specific dopamine uptake mechanism in either astrocytes or MSNs would further limit dopamine metabolism and $\mathrm{H}_{2} \mathrm{O}_{2}$ production by MAO in these cell types. Importantly, suppression of dopamine release by modulatory 
$\mathrm{H}_{2} \mathrm{O}_{2}$ persists when the DAT is inhibited (Avshalumov et al., 2003), implying a lack of contribution from metabolism of released dopamine by MAO-A in dopaminergic axons as well. In contrast to neuron-glia segregation of MAO isoforms, there is evidence for Nox expression in striatal MSNs and in surrounding neuropil, although the specific distribution remains unresolved (Serrano et al., 2003; Kim et al., 2005).

Mitochondria are abundant in neuronal axons and dendrites, including dopaminergic axons in striatum. However, the absence of ionotropic glutamate receptors on dopaminergic axons (Bernard and Bolam, 1998; Chen et al., 1998) and the lack of effect of GYKI-42466 or MCS on dopamine release evoked by selective dopamine pathway stimulation (Avshalumov et al., 2008) suggest that these are not the site of glutamatedependent, mitochondrial $\mathrm{H}_{2} \mathrm{O}_{2}$ generation. Rather, our previous studies suggest that generation of modulatory $\mathrm{H}_{2} \mathrm{O}_{2}$ occurs predominantly in MSNs (Avshalumov et al., 2008), which are the principal output cells of the striatum that compose $90-95 \%$ of the striatal neuron population (Kemp and Powell, 1971). Interestingly, glutamate synapses are closely apposed to dopamine synapses on the dendritic spines of these neurons (Smith and Bolam, 1990; Bernard and Bolam, 1998; Chen et al., 1998), placing them in an ideal position to modulate axonal dopamine release via diffusible $\mathrm{H}_{2} \mathrm{O}_{2}$. This anatomical organization and the dependence of $\mathrm{H}_{2} \mathrm{O}_{2}$ on synaptic glutamate release help ensure temporally and spatially discrete modulation of dopamine release by this process, which adds another dimension to the current understanding of signaling specificity for $\mathrm{H}_{2} \mathrm{O}_{2}$ and other ROS (D'Autréaux and Toledano, 2007).

The site of $\cdot \mathrm{O}_{2}{ }^{-}$and hence $\mathrm{H}_{2} \mathrm{O}_{2}$ generation within mitochondria is currently under debate. Studies in isolated mitochondria have shown that blockade of either complex I or III can increase ROS generation (Cadenas et al., 1977; Votyakova and Reynolds, 2001; Liu et al., 2002; Servais et al., 2003, Gyulkhandanyan and Pennefather, 2004; Adam-Vizi, 2005). Consistent with such data, partial inhibition of complex I by nanomolar concentrations of rotenone also increases ROS generation in MSNs in striatal slices (Bao et al., 2005). We show here that nanomolar rotenone reversed succinate-induced $\mathrm{H}_{2} \mathrm{O}_{2}$ generation and consequent suppression of dopamine release, presumably by blocking succinate-driven $\mathrm{H}_{2} \mathrm{O}_{2}$ generation at complex I. These data support a role for complex I in the generation of modulatory $\mathrm{H}_{2} \mathrm{O}_{2}$. The findings may also have relevance for understanding the pathophysiology of Parkinson disease, as postmortem tissues from individuals with Parkinson disease show a deficiency in complex I activity (Schapira et al., 1990) as well as oxidative damage (for review, see Lin and Beal, 2006).

\section{Conclusions and implications}

The data presented show that mitochondria are the source of modulatory $\mathrm{H}_{2} \mathrm{O}_{2}$ in the striatum, a key brain region in motor control. Additional evidence indicates that the two other sources of $\mathrm{H}_{2} \mathrm{O}_{2}$ generation, MAO and Nox, do not contribute to dynamic, subsecond $\mathrm{H}_{2} \mathrm{O}_{2}$ signaling in the striatum. Of course, these enzymes have other critical roles in the CNS, including the key role of MAO in dopamine metabolism (Azzaro et al., 1985; Cohen et al., 1997) and the wide range of functional consequences of Nox-dependent generation of $\mathrm{H}_{2} \mathrm{O}_{2}$ and other ROS over longer time scales than those examined here (Lambeth, 2004; Rhee et al., 2005; Infanger et al., 2006; Miller et al., 2007b; Bedard and Krause, 2007; Kishida and Klann, 2007). The lack of contribution of $\mathrm{MAO}$ and Nox to rapid $\mathrm{H}_{2} \mathrm{O}_{2}$ signaling indicates that mitochondria alone provide a temporally linked response to neuronal activity that generates a sufficiently rapid, but controlled elevation in $\mathrm{H}_{2} \mathrm{O}_{2}$ required for ion channel activation. The present studies mark the first step in elucidating different layers of regulation by $\mathrm{H}_{2} \mathrm{O}_{2}$ that can be defined by the time course of $\mathrm{H}_{2} \mathrm{O}_{2}$ generation.

The findings reported here also help define characteristics of physiological versus pathophysiological roles of $\mathrm{H}_{2} \mathrm{O}_{2}$ in the CNS. Chronic exposure to low levels of $\mathrm{H}_{2} \mathrm{O}_{2}$ formed from dopamine metabolism by MAO has been proposed to contribute to oxidative stress in the slow degeneration of dopaminergic neurons in the substantia nigra pars compacta in Parkinson disease (Cohen et al., 1997). Similarly, Nox-derived superoxide contrib- 
utes to the pathological consequences of exposure to rotenone and to other neurotoxins that target the nigrostriatal dopamine pathway (Gao et al., 2003; Wu et al., 2003). The time frame required for the development of such pathophysiological consequences is days to years. This contrasts sharply with the subsecond time frame of the transient mitochondrial $\mathrm{H}_{2} \mathrm{O}_{2}$ elevation and consequent $\mathrm{K}_{\mathrm{ATP}}$-channel opening that mediate the reversible inhibition of striatal dopamine release by glutamate.

\section{References}

Adam-Vizi V (2005) Production of reactive oxygen species in brain mitochondria: contribution by electron transport chain and non-electron transport chain sources. Antioxid Redox Signal 7:1140-1149.

Atkins CM, Sweatt JD (1999) Reactive oxygen species mediate activitydependent neuron-glia signaling in output fibers of the hippocampus. J Neurosci 19:7241-7248.

Avshalumov MV, Rice ME (2003) Activation of ATP-sensitive $\mathrm{K}^{+}\left(\mathrm{K}_{\mathrm{ATP}}\right)$ channels by $\mathrm{H}_{2} \mathrm{O}_{2}$ underlies glutamate-dependent inhibition of striatal dopamine release. Proc Natl Acad Sci U S A 100:11729-11734.

Avshalumov MV, Chen BT, Marshall SP, Peña DM, Rice ME (2003) Glutamate-dependent inhibition of dopamine release in striatum is mediated by a new diffusible messenger, $\mathrm{H}_{2} \mathrm{O}_{2}$. J Neurosci 23:2744-2750.

Avshalumov MV, MacGregor DG, Sehgal LM, Rice ME (2004) The glial antioxidant network and neuronal ascorbate: protective yet permissive for $\mathrm{H}_{2} \mathrm{O}_{2}$ signaling. Neuron Glia Biol 1:365-376.

Avshalumov MV, Chen BT, Koós T, Tepper JM, Rice ME (2005) Endogenous hydrogen peroxide regulates the excitability of midbrain dopamine neurons via ATP-sensitive potassium channels. J Neurosci 25:4222-4231.

Avshalumov MV, Bao L, Patel JC, Rice ME (2007) $\mathrm{H}_{2} \mathrm{O}_{2}$ signaling in the nigrostriatal dopamine pathway via ATP-sensitive potassium channels: issues and answers. Antioxid Redox Signal 9:219-231.

Avshalumov MV, Patel JC, Rice ME (2008) AMPA receptor-dependent $\mathrm{H}_{2} \mathrm{O}_{2}$ generation in striatal medium spiny neurons, but not dopamine axons: one source of a retrograde signal that can inhibit dopamine release. J Neurophysiol 100:1590-1601.

Azzaro AJ, King J, Kotzuk J, Schoepp DD, Frost J, Schochet S (1985) Guinea pig striatum as a model of human dopamine deamination: the role of monoamine oxidase isozyme ratio, localization, and affinity for substrate in synaptic dopamine metabolism. J Neurochem 45:949-956.

Bao L, Avshalumov MV, Rice ME (2005) Mitochondrial inhibition causes functional dopamine denervation and striatal medium spiny neurons depolarization via increased $\mathrm{H}_{2} \mathrm{O}_{2}$, not decreased ATP. J Neurosci 25:10029-10040.

Bedard K, Krause KH (2007) The NOX family of ROS-generating NADPH oxidases: physiology and pathophysiology. Physiol Rev 87:245-313.

Bernard V, Bolam JP (1998) Subcellular and subsynaptic distribution of the NR1 subunit of the NMDA receptor in the neostriatum and globus pallidus of the rat: colocalization at synapses with the GluR2/3 subunit of the AMPA receptor. Eur J Neurosci 10:3721-3736.

Bernard V, Somogyi P, Bolam JP (1997) Cellular, subcellular, and subsynaptic distribution of AMPA-type glutamate receptor subunits in the neostriatum of the rat. J Neurosci 17:819-833.

Betarbet R, Sherer TB, MacKenzie G, Garcia-Osuna M, Panov AV, Greenamyre JT (2000) Chronic systemic pesticide exposure reproduces features of Parkinson's disease. Nat Neurosci 3:1301-1306.

Bonnet U, Leniger T, Wiemann M (2000) Moclobemide reduces intracellular $\mathrm{pH}$ and neuronal activity of CA3 neurones in guinea-pig hippocampal slices-implication for its neuroprotective properties. Neuropharmacology 39:2067-2074.

Boveris A, Chance B (1973) The mitochondrial generation of hydrogen peroxide: general properties and the effect of hyperbaric oxygen. Biochem J 134:707-716

Cadenas E, Boveris A, Ragan CI, Stoppani AO (1977) Production of superoxide radicals and hydrogen peroxide by $\mathrm{NADH}$-ubiquinone reductase and ubiquinol-cytochrome c reductase from beef-heart mitochondria. Arch Biochem Biophys 180:248-257.

Chen BT, Rice ME (2001) Novel $\mathrm{Ca}^{2+}$ dependence and time course of somatodendritic dopamine release: substantia nigra versus striatum. J Neurosci 21:7841-7847.

Chen Q, Veenman L, Knopp K, Yan Z, Medina L, Song WJ, Surmeier DJ, Reiner A (1998) Evidence for the preferential localization of glutamate receptor-1 subunits of AMPA receptors to the dendritic spines of medium spiny neurons in rat striatum. Neuroscience 83:749-761.

Cohen G, Farooqui R, Kesler N (1997) Parkinson disease: a new link between monoamine oxidase and mitochondrial electron flow. Proc Natl Acad Sci U S A 94:4890-4894.

Cragg SJ, Rice ME (2004) DAncing past the DAT at a DA synapse. Trends Neurosci 27:270-277.

D’Autréaux B, Toledano MB (2007) ROS as signalling molecules: mechanisms that generate specificity in ROS homeostasis. Nat Rev Mol Cell Biol 8:813-824.

Davey GP, Clark JB (1996) Threshold effects and control of oxidative phosphorylation in nonsynaptic rat brain mitochondria. J Neurochem 66:1617-1624.

Doussière J, Bouzidi F, Vignais PVA (2001) phenylarsine oxide-binding protein of neutrophil cytosol, which belongs to the S100 family, potentiates NADPH oxidase activation. Biochem Biophys Res Comm 285:1317-1320.

Dykens JA (1994) Isolated cerebral and cerebellar mitochondria produce free radicals when exposed to elevated $\mathrm{Ca}^{2+}$ and $\mathrm{Na}^{+}$: implications for neurodegeneration. J Neurochem 63:584-591.

Francis A, Pearce LB, Roth JA (1985) Cellular localization of MAO A and B in brain: evidence from kainic acid lesions in striatum. Brain Res 334:59-64.

Fuxe K, Agnati LF (1991) Volume transmission in the brain. New York: Raven.

Gao HM, Liu B, Hong JS (2003) Critical role for microglial NADPH oxidase in rotenone-induced degeneration of dopaminergic neurons. J Neurosci 23:6181-6187.

Gyulkhandanyan AV, Pennefather PS (2004) Shift in the localization of sites of hydrogen peroxide production in brain mitochondria by mitochondrial stress. J Neurochem 90:405-421.

Hersch SM, Yi H, Heilman CJ, Edwards RH, Levey AI (1997) Subcellular localization and molecular topology of the dopamine transporter in the striatum and substantia nigra. J Comp Neurol 388:211-227.

Infanger DW, Sharma RV, Davisson RL (2006) NADPH oxidases of the brain: distribution, regulation, and function. Antioxid Redox Signal 8:1583-1596.

Kamsler A, Segal M (2004) Hydrogen peroxide as a diffusible signal molecule in synaptic plasticity. Mol Neurobiol 29:167-178.

Kemp JM, Powell TP (1971) The structure of the caudate nucleus of the cat: light and electron microscopy. Philos Trans R Soc Lond B Biol Sci 262:383-401.

Kim MJ, Shin KS, Chung YB, Jung KW, Cha CI, Shin DH (2005) Immunohistochemical study of p47Phox and gp91Phox distributions in rat brain. Brain Res 1040:178-186.

Kishida KT, Klann E (2007) Sources and targets of reactive oxygen species in synaptic plasticity and memory. Antioxid Redox Signal 9:233-244.

Lambeth JD (2004) NOX enzymes and the biology of reactive oxygen. Nat Rev Immunol 4:181-189.

Levitt P, Maxwell GD, Pintar JE (1985) Specific cellular expression of monoamine oxidase B during early stages of quail embryogenesis. Dev Biol 110:346-361.

Lin MT, Beal MF (2006) Mitochondrial dysfunction and oxidative stress in neurodegenerative diseases. Nature 443:787-795.

Liu Y, Fiskum G, Schubert D (2002) Generation of reactive oxygen species by the mitochondrial electron transport chain. J Neurochem 80:780-787.

Maker HS, Weiss C, Silides DJ, Cohen G (1981) Coupling of dopamine oxidation (monoamine oxidase activity) to glutathione oxidation via the generation of hydrogen peroxide in rat brain homogenates. J Neurochem 36:589-593.

Miller EW, Bian SX, Chang CJ (2007a) A fluorescent sensor for imaging reversible redox cycles in living cells. J Am Chem Soc 129:3458-3459.

Miller EW, Tulyathan O, Tulyanthan O, Isacoff EY, Chang CJ (2007b) Molecular imaging of hydrogen peroxide produced for cell signaling. Nat Chem Biol 3:263-267.

Nirenberg MJ, Vaughan RA, Uhl GR, Kuhar MJ, Pickel VM (1996) The dopamine transporter is localized to dendritic and axonal plasma membranes of nigrostriatal dopaminergic neurons. J Neurosci 16:436-447.

Patel JC, Witkovsky P, Avshalumov MV, Rice ME (2009) Mobilization of intracellular calcium stores facilitates somatodendritic dopamine release. J Neurosci 29:6568-6579. 
Ramón y Cajal S (1909) Histologie du système nerveux de l'homme et des vertébrés. Madrid: Instituto "Ramón y Cajal."

Rhee SG (2006) $\mathrm{H}_{2} \mathrm{O}_{2}$, a necessary evil for cell signaling. Science 312:1882-1883.

Rhee SG, Kang SW, Jeong W, Chang TS, Yang KS, Woo HA (2005) Intracellular messenger function of hydrogen peroxide and its regulation by peroxiredoxins. Curr Opin Cell Biol 17:183-189.

Rice ME, Cragg SJ (2008) Dopamine spillover after quantal release: rethinking dopamine transmission in the nigrostriatal pathway. Brain Res Rev 58:303-313.

Rice ME, Richards CD, Nedergaard S, Hounsgaard J, Nicholson C, Greenfield SA (1994) Direct monitoring of dopamine and 5-HT release in substantia nigra and ventral tegmental area in vitro. Exp Brain Res 100:395-406.

Schaefer T, Wiedemann C, Gitler C, Burger MM (1994) Effects of arsenicals on the secretory process in chromaffin cells. Ann N Y Acad Sci 710:356-367.

Schapira AH, Cooper JM, Dexter D, Clark JB, Jenner P, Marsden CD (1990) Mitochondrial complex I deficiency in Parkinson's disease. J Neurochem 54:823-827.

Serrano F, Kolluri NS, Wientjes FB, Card JP, Klann E (2003) NADPH oxidase immunoreactivity in the mouse brain. Brain Res 988:193-198.

Servais S, Couturier K, Koubi H, Rouanet JL, Desplanches D, Sornay-Mayet MH, Sempore B, Lavoie JM, Favier R (2003) Effect of voluntary exercise on $\mathrm{H}_{2} \mathrm{O}_{2}$ release by subsarcolemmal and intermyofibrillar mitochondria. Free Radic Biol Med 35:24-32.

Sesack SR, Aoki C, Pickel VM (1994) Ultrastructural localization of D2receptor-like immunoreactivity in midbrain dopamine neurons and their striatal targets. J Neurosci 14:88-106.

Sherer TB, Betarbet R, Testa CM, Seo BB, Richardson JR, Kim JH, Miller GW,
Yagi T, Matsuno-Yagi A, Greenamyre JT (2003) Mechanism of toxicity in rotenone models of Parkinson's disease. J Neurosci 23:10756-10764.

Smith AD, Bolam JP (1990) The neural artwork of the basal ganglia as revealed by the study of synaptic connections of identified neurons. Trends Neurosci 13:259-265.

Veal EA, Day AM, Morgan BA (2007) Hydrogen peroxide sensing and signaling. Mol Cell 26:1-14.

Vizi ES (2000) Role of high-affinity receptors and membrane transporters in nonsynaptic communication and drug action in the central nervous system. Pharmacol Rev 52:63-89.

Votyakova TV, Reynolds IJ (2001) $\Delta \Psi_{\mathrm{m}}$-Dependent and-independent production of reactive oxygen species by rat brain mitochondria. J Neurochem 79:266-277.

Weinberg JM, Venkatachalam MA, Roeser NF, Saikumar P, Dong Z, Senter RA, Nissim I (2000) Anaerobic and aerobic pathways for salvage of proximal tubules from hypoxia-induced mitochondrial injury. Am J Physiol Renal Physiol 279:F927-F943.

Wu DC, Teismann P, Tieu K, Vila M, Jackson-Lewis V, Ischiropoulos H, Przedborski S (2003) NADPH oxidase mediates oxidative stress in the 1-methyl-4-phenyl-1,2,3,6-tetrahydropyridine model of Parkinson's disease. Proc Natl Acad Sci U S A 100:6145-6150.

Yodoya E, Wada M, Shimada A, Katsukawa H, Okada N, Yamamoto A, Ganapathy V, Fujita T (2006) Functional and molecular identification of sodium-coupled dicarboxylate transporters in rat primary cultured cerebrocortical astrocytes and neurons. J Neurochem 97:162-173.

Yung KK, Bolam JP, Smith AD, Hersch SM, Ciliax BJ, Levey AI (1995) Immunocytochemical localization of D1 and D2 dopamine receptors in the basal ganglia of the rat: light and electron microscopy. Neuroscience 65 : $709-730$. 